\title{
Toxicity of Legiayu incense as Insecticide and Larvicide Against Aedes aegypti Mosquitoes Mortality
}

\author{
I Made Dwi Mertha Adnyana ${ }^{1,2 *}$, Ni Luh Gede Sudaryati' ${ }^{1}$ Israil Sitepu1
}

1. Department of Biology, Faculty of Information Technology and Science, Hindu University of Indonesia, Jl. Sangalangit Tembau Penatih 80236, Denpasar, Indonesia

2. Master Program of Tropical Medicine, Faculty of Medicine, Airlangga University Jl. Prof. Moestopo No 47, Pacar Kembang, 60132, Surabaya, Indonesia

\begin{tabular}{|c|c|}
\hline Info Article & ABSTRACT \\
\hline $\begin{array}{l}\text { Submitted: } 28-09-2021 \\
\text { Revised: } 21-09-2021 \\
\text { Accepted: } 16-12-2021 \\
\text { *Corresponding author } \\
\text { I Made Dwi Mertha Adnyana }\end{array}$ & $\begin{array}{l}\text { Community-based DHF vector control has been implemented in } \\
\text { Indonesia but has not yet obtained optimal results. Thus, in the community } \\
\text { choosing synthetic insecticides to control disease vectors. Long term and } \\
\text { excessive using of insecticides enable a toxic effect and resistance to } \\
\text { mosquitoes. Burning of mosquitoes coils and incense containing synthetic } \\
\text { dyes and fragrances have the potential to reduce environmental quality. This } \\
\text { research was conducted to analyze the toxicity of Legiayu incense as an } \\
\text { insecticide and larvicide against Aedes aegypti mosquito mortality. The } \\
\text { research design is experimental with a completely randomized design. } \\
\text { Testing was conducted by providing exposure to smoke and ash of Legiayu } \\
\text { incense five times on twenty-five Aedes aegypti mosquitoes. Statistical } \\
\text { analysis used one-way ANOVA, and probit test. The result showed that } \\
\text { insecticides effective exposure for } 20 \text { minutes with a durability of } 6 \text { hours } \\
\text { (p=0.000), while as larvicide effective exposure for } 24 \text { hours ( } p=0.000 \text { ). } \\
\text { Exposure Legiayu incense smoke obtained an LT } 50 \text { value of } 09012 \leq 5 \text { (super } \\
\text { toxic category) with a time of } 15 \text { minutes } 39 \text { seconds, } \mathrm{R}^{2} \text { of } 99.24 \% \text {, and } \mathrm{r} \text { of } \\
\text { 99.62\% while exposure to the ash of Legiayu incense obtained LT } 50 \text { value of } \\
0,058965 \text { (super toxic category) with time } 19 \text { hours } 15 \text { minutes } 34 \text { seconds, } \\
\mathrm{R}^{2} \text { and r of } 100 \% \text {. Histopathological test results showed that Legiayu incense } \\
\text { smoke did not cause tissue degeneration, necrosis, hyperplasia, and } \\
\text { metaplasia in the lung tissue of mice (Mus musculus) in } 12 \text { weeks period. Thus, } \\
\text { Legiayu incense is effective as insecticides and larvicides against Aedes aegypti } \\
\text { mosquitoes and-potential substitute for mosquito repellent synthetic incense. } \\
\text { Key words: Aedes aegypti, Insecticide, Larvicide, Legiayu incense, Toxicity. }\end{array}$ \\
\hline
\end{tabular}

\section{INTRODUCTION}

Aedes aegypti mosquito is dengue virus vector transmitted on the human body (Ministry of Health, 2018). The number of Dengue Hemorrhagic Fever (DHF) cases in Indonesia from 2006-2015, 57\% of the cases are from Indonesia (Mayasari et al., 2020). A very significant increase in incidence rate (IR). DHF is widespread in the Indonesian Province of Bali. In Bali Province in 2019, a total of 5.956 cases of dengue occurred, with the IR was $137.3>49$ per 100.000 people. It is considerably higher than the national (Bali Health Department, 2020).

High cases of DHF in Bali may be due to the application of the 3M Plus program are not going well and low of community participation. Furthermore, the increased use of synthetic insecticides, which is causing a decline in environmental standards and mosquitoes experiencing resistance (Garcia et al., 2018; Marcombe et al., 2017). The substance of synthetic insecticides has positive attributes as an insect repellent and has adverse health effects due to high acetylcholine accumulation levels (Wong et al., 2020) with the symptoms include vomiting, muscle spasms, bradycardia, paralysis, and death (Hung et al., 2020; Jerry et al., 2012). Environmental quality degradation is caused by the excessive use of synthetic insecticides. Besides, the use of synthetic dye incense and fragrances is increasing significantly in Bali. This synthetic fragrance contains carcinogenic substances which pollute the air (Amador-Muñoz et al., 2020; Geng et al., 2017) 
and produce environmental damage (Guo et al., 2020). The high side effects and impacts of the use of incense containing synthetic fragrances resulted in people switching to utilizing natural ingredients because it is considered safer for health, cheaper, and environmentally friendly (Susilowati et al., 2018; Zulfikar et al., 2019).

Based on this, developing environmentally friendly incense organic raw materials such as Legundi leaf (Vitex trifolia L.), lemongrass leaves (Andropogon nardus), and wood grain packaged in Legiayu incense, are necessary The pharmacologically content of oleum citronellal, geraniol, tannin, flavonoids, saponins, champine, pinine and polyphenols that serve as insecticides and larvicide (Bao et al., 2018; Chan et al., 2016). These compound has benefits as contact, stomach and respiratory toxins that result in death (Susilowati et al., 2018). Legiayu incense has potential a substitute for mosquito an organic repellents-synthetic fragrance-based incense. The objective of this research was to analyze the toxicity of Legiayu incense as insecticide and larvicide against Aedes aegypti mosquito mortality. The results of this research are initial efforts to prevent, and suppress of Aedes aegypti mosquitoes by developing herbal products based on local wisdom which is effective, safe, are not toxins and no environmental pollution.

\section{MATERIAL AND METHODS}

The material research were Aedes aegypti imago mosquitoes aged 3 weeks and larvae aged 6 days (Instar IV) and 8 weeks old strain Balb/c (25 tails) mice weighing 24-35 gr. The tools used were 2 large buckets, $50 \mathrm{~mL}$ platic glass, test tube, 4piece drop pipette, digital scale, measuring flask, cutter, medium size scissors, petri dish, filter research, Peet Grady Chamber size $45 \times 45 \times 45 \mathrm{~cm}^{3}$, sterile handscone, cotton, hygrometer $\AA$, sterile gauze, tissue, room thermometer, glass asprirator $\AA$, gas lighter, stopwatch $\AA$, gadgets and stationery. While the materials used in this research were Aedes aegypti mosquito eggs as many as 1.250 grains, temephos $1 \% \AA$, mosquito repellent coils contain transfluthrin $\AA 1$ box, Legiayu incense, water, fish pellets brand takari $\AA$, and sugar $50 \mathrm{~g}$.

\section{Research design}

This experimental research follows to Completely Randomyzed Design (CRD), completed from January to June 2020, in Entomology
Laboratory, Department of Biology, Hindu University of Indonesia, UPTD. Balai Hyperkes \& Work Safety and National Agency of Drug \& Food Bali Province.

\section{Testing legiayu incense as insecticide}

The treatment in this research gave exposure Legiayu incense to 25 heads of adult population of Aedes aegypti mosquitoes with a different time of 10, 20, 30 and 40 minutes also 0 minutes (as control) negative control (no treatment) and positive control (with repellent burn), Replication are five times with a total sample of 750 Aedes aegypti mosquitoes.

\section{Testing legiayu incense as larvicides}

The testing as larvacide was conducted by pouring $100 \mathrm{mg}$ ash from the burning of Legiayu incense to test tube that has been filled with 25 heads of larvae of the 6-day-old Aedes aegypti mosquito (instar IV) replicatioans are five times with an incubation period of 12 and 24 hours, 2 (negative control and positive control (temephos 1\%®), the total sample was 500 Aedes aegypti mosquito larvae.

\section{Toxicology and histopathology testing}

Testing of smoke and ash toxicity of Legiayu incense was conducted through the calculation of the number of Aedes aegypti mosquito mortality after being treated with Lethal Time (LT50) parameters or exposure time resulting in larvae and imago experiencing death of $50 \%$ of the total population (OECD, 2009). Histopathology testing was conducted to determine the histological picture of rat lung tissue (Mus musculus) after being given exposure to Legiayu smoke incense for 12 weeks. The test was conducted in the Food and Drug Administration of Bali Province. Legiayu incense smoke was tested for toxicity by exposing BALB/c strain mice to incense smoke for 40 minutes every day for a period of 12 weeks. Mice that had been exposed were subsequently physically sacrificed by having their necks dislocated. If the animal is deceased, do surgery to extract the lungs and proceed with histological preparations using Hematoxylin Eosin (HE) staining.These results are used to analyze the impact of Legiayu incense smoke exposure as well as analyze the damage caused (OECD, 2018). The testing the safety of smoke and ash of Legiayu incense in the UPTD. Balai Hiperkes \& work safety Bali Province. 
Table I. The mortality rate of Aedes aegypti mosquitoes exposed to different times

\begin{tabular}{ccccc}
\hline Treatment & Mean \pm SE & Shapiro Wilk & Levene Statistic & ANOVA \\
\hline K(-) & $00.00 \pm 0.000 \mathrm{a}$ & 0.000 & & \\
K(+) & $15.40 \pm 2.522 \mathrm{~b}$ & 0.739 & & \\
P1 & $11.40 \pm 1.860 \mathrm{~b}$ & 0.617 & 0.031 & \\
P2 & $17.80 \pm 1.530 \mathrm{c}$ & 0.814 & \\
P3 & $23.40 \pm 0.510 \mathrm{~d}$ & 0.814 & \\
P4 & $24.20 \pm 0.837 \mathrm{~d}$ & 0.314 & & \\
\hline
\end{tabular}

Abbreviations: SE= Standard error; ${ }^{* *}=$ Very significantly different $(p<0.01)$; Numbers with letters = Very significant differences $(p<0.01)$.

\section{Population and samples}

The Aedes aegypti mosquitoes were collected from the Entomology Laboratory at the East Java Health Office in Surabaya. The samples used Aedes aegypti with a criteria three-weeks for testing as insecticides and larvae aged six days for testing as larvicides. The number of treatments and repeats in this research is based on World Health Organization Pesticides Evaluation Scheme procedures (WHOPES, 2018). The Health Science Ethics Commission (KEPK) Denpasar Health Polytechnic approved the use of Aedes aegypti mosquitoes and rats (Mus musculus) strain Balb/C as a research study with Ethical Approval number LB.02.03/EA/KEPK/0113/2020.

\section{Statistical analysis}

The mortality of Aedes aegypti larvae and imago was analyzed by a one-way ANOVA test, followed by a Fisher's least significant defference (LSD) post hoc test with a significance level of $(p<0.01)$. The toxicity test uses the Unit Probability (Probit) test to obtain a Lethal Time value of $50 \%$ $\left(\mathrm{LT}_{50}\right)$. Data is presented in the form of tables, graphs, pictures and narration. This data was compiled using the Statistical Product and Service Solutions (SPSS) Inc. 25.0.

\section{RESULT AND DISCUSSION \\ Legiayu incense smoke as an insecticide}

The Shapiro-wilk normality test revealed that the probability value between treatment groups was normally distributed $(p>0.01)$. The Levene test results revealed that the variance value was homogeneous $(p=0.031)$, which was greater than $p>0.01$. The one-way ANOVA test results (Table I) revealed that the probability value $(p=0.000)$ was smaller than $p<0.01$. Thus, exposure to Legiayu incense smoke among the treatment $(10,20,30$, and 40 minutes \& control) had a very significant effect on the mortality of Aedes aegypti mosquitoes. The LSD test showed that the treatments of negative control $(\mathrm{K}-)$, positive control $(\mathrm{K}+)$, and exposure treatment for 20 minutes (P2) are very significantly different $(\mathrm{p}<0.01)$. While exposure to Legiayu incense smoke for 30 minutes (P3) compared to exposure for 40 minutes (P4) was not significant ( $p>0.01$ ) (Table I).

Based on the unit probability test, exposure of Legiayu incense smoke to the mortality of imago Aedes aegypti mosquitos received a signification value $(p=0.000)$ smaller than value $(p<0.01)$. Thus, there is an effect of exposure time to Legiayu incense (X) smoke on the mortality of Aedes aegypti mosquitoes (Y). The result of the Lethal Time 50\% test on the mortality of the imago Aedes aegypti mosquito given exposure to Legiayu incense smoke at different times obtained $\mathrm{LT}_{50}$ value of $0.9012 \leq 5$ (super toxic category). Thus, exposure to Legiayu incense smoke was able to result in 50\% mortality of imago Aedes aegypti mosquitoes within 15 minutes 39 seconds. The results of the analysis of the relationship between exposure time to Legiayu incense smoke (Figure 1) shows the value of variable regression coefficient of smoke exposure time range $(\mathrm{X})$ of 0.0753 means that if there is an increase of 1 minute after exposure to Legiayu incense smoke, the mortality of imago Aedes aegypti mosquitoes (Y) will increase by $7.53 \%$, coefficient of determination $\left(\mathrm{R}^{2}\right)$ of $0.9924(99,24 \%)$ thus, the mortality of Aedes aegypti mosquitoes was influenced by the length of time exposure to Legiayu incense smoke. While the correlation coefficient value (r) is 0.9962 (99.62\%) the relationship between the time of smoke exposure and the mortality rate of imago is very strong (Darwin et al., 2021).

Based on the smoke testing Legiayu incense as an insecticide there is an increase in the mortality of Aedes aegypti mosquitoes, after exposure to Legiayu incense smoke. 


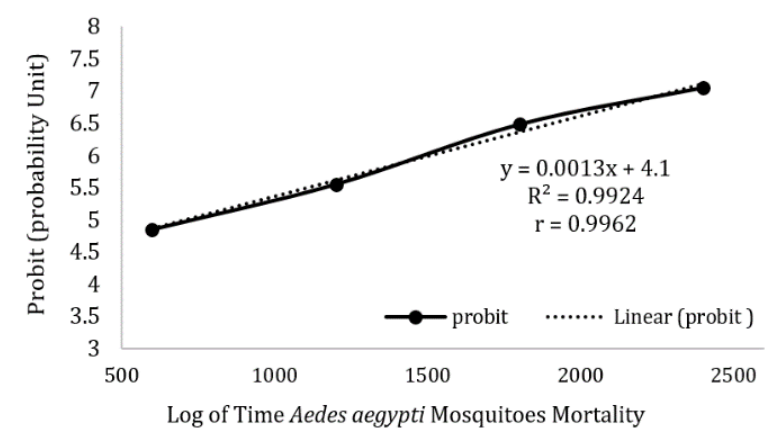

Figure 1. Relationship of exposure time to Aedes aegypti mosquitoes mortality

It is caused by compounds in Legiayu incense such as essential oils, chalcone, dyhidrocalcon, flavonoids, 3-geranilflavones, xanthones, saponins, tannins, polyphenols and alkhaloids that inhibiting the excitatory power of eating insects, inhibitors of the respiratory system and inhibiting moulting hormones (Saklani et al., 2017; Siew et al., 2019). Legiayu incense have an effect as insecticides such as flavonoids, saponins, citoronellal, and polyphenols. The mode of action of these flavonoid compounds is inhibiting effect on the respiratory poison. If the insect inhales Legiayu incense smoke will breathing disorders and excessive dehydration and result in death (Saputra and Pakkan, 2018). Saponin and citronellal compounds are able to decrease the elasticity of the surface of the insect's body, lower the turgor voltage of the insect's body, as a result of skin trauma and die of dryness (Ekawati, 2017; Susilowati et al., 2018). Polyphenol compounds can provide an insecticidal effect by binding to factor adhesions, extra cellular proteins and soluble proteins resulting in increased damage to cuticles and cells that have an impact on the decrease in the ability in producing colinesterase enzymes for the growth and transport of food throughout the body, resulting in insect death (Aji, 2017). Based on this, the use of raw materials of lemongrass leaves and legundi effective as an insecticide (Fitriansyah et al., 2018). The impact of use of these ingredients provide healthty, environmentaly, minimizing of side effects and pollution. Also, the use of smoking methods is an effective apply of insecticide (EPA, 2014).

\section{Legiayu incense smoke as an larvicide}

The Shapiro-Wilk normality analysis showed that the probability value between treatment groups was normally distributed $(p>0.01)$. The Levene test results showed that the variance value was homogeneous $(p=0.080)$ was greater than $p>0.01$. The one-way ANOVA test analysis (Table III) showed that the probability value $(p=0.000)$ was less than $p<0.01$. Thus, exposure to Legiayu incense ash had a very significant impact on Aedes aegypti mosquito larvae mortality. The LSD test showed that the treatment of the positive control (K+), treatment of $12 \mathrm{~h}(\mathrm{P} 1)$, and treatment of $24 \mathrm{~h}$ (P2) were not significantly different $(p>0.01)$ (Table II).

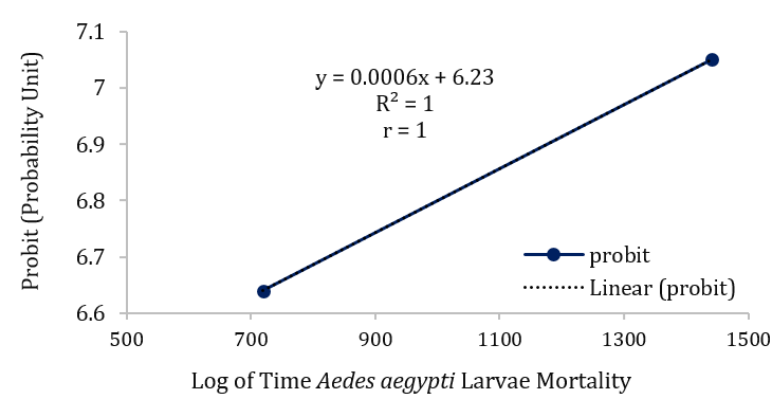

Figure 2. Relationship of ash exposure time to mortality of mosquito larvae.

Based on the unit probability test, among treatmen of exposure of Legiayu incense ash to the mortality of Aedes aegypti mosquito larvae obtained a signification value $(p=0.000)$ smaller than the value $(\mathrm{p}<0.01)$. Thus, this indicated that exposure time of Legiayu incense (X) ash affect on the mortality of larvae Aedes aegypti mosquitoes (Y). The Lethal Time $50 \%$ analysis results on the mortality of Aedes aegypti mosquito larvae exposure to Legiayu incense ash at different times obtained $\mathrm{LT}_{50}$ a value of $0,05896 \leq 5$ (super toxic category). Thus, exposure to Legiayu incense ash was able to result in 50\% mortality of Aedes aegypti mosquito larvae within $19 \mathrm{~h} 15 \mathrm{~min} 34 \mathrm{~s}$. The analysis of the relationship between exposure time to Legiayu incense ash (Figure 2) showed the regression coefficient of ash exposure time range (X) of 0.0342 means that if there is an increase of 1 hours after exposure to Legiayu incense ash, the mortality rate of Aedes aegypti mosquito larvae (Y) would increase by $3.42 \%$, with a coefficient of determination $\left(\mathrm{R}^{2}\right)$ of one, implying that the time of exposure to Legiayu incense ash has a $100 \%$ effect on the mortality rate of Aedes aegypti mosquito larvae. While the correlation coefficient (r) is 1 (100\%) the relationship between the time of exposure to ash and the mortality rate of larvae is perfect. 
Table II.The mortality rate of larvae Aedes aegypti mosquitoes exposed to different times

\begin{tabular}{ccccc}
\hline Group & Mean \pm SE & Shapiro Wilk & Levene Statistic & ANOVA \\
\hline $\mathrm{K}(-)$ & $00.00 \pm 0.000 \mathrm{a}$ & 0.000 & & $0.000^{* *}$ \\
$\mathrm{~K}(+)$ & $23.20 \pm 1.700 \mathrm{~b}$ & 0.421 & 0.080 & \\
$\mathrm{P} 1$ & $23.80 \pm 1.700 \mathrm{~b}$ & 0.421 & & \\
$\mathrm{P} 2$ & $24.40 \pm 0.800 \mathrm{~b}$ & 0.046 & & \\
\hline
\end{tabular}

Abbreviations: $\mathrm{SE}=$ Standard error; ${ }^{* *}=$ Very significantly different $(\mathrm{p}<0.01)$; Numbers with letters = Very significant differences $(\mathrm{p}<0.01)$.

Table III. Laboratory results of smoke and ash safety Legiayu incense

\begin{tabular}{lcccccc}
\hline \multirow{2}{*}{ Parameter } & \multirow{2}{*}{ Unit } & \multicolumn{3}{c}{ Test Results } & \multirow{2}{*}{ Quality Standard } & \multirow{2}{*}{ Test Result } \\
\cline { 3 - 5 } & & $\mathbf{A 2 9 8}$ & $\mathbf{A ~ 2 9 9}$ & $\mathbf{A ~ 3 0 0}$ & & \\
\hline $\mathrm{PM}_{2,5}$ & $\mu \mathrm{g} / \mathrm{Nm}^{3}$ & 0.5 & 0.7 & 0.9 & 66 & Safe \\
Nitrogen Dioxide $\left(\mathrm{NO}_{2}\right)$ & $\mu \mathrm{g} / \mathrm{Nm}^{3}$ & 0.2 & 0.4 & 0.2 & 400 & Safe \\
Sulfur Dioxide $\left(\mathrm{SO}_{2}\right)$ & $\mu \mathrm{g} / \mathrm{Nm}^{3}$ & 3.48 & 3.69 & 1.78 & 900 & Safe \\
Carbon Monoxide $(\mathrm{CO})$ & $\mu \mathrm{g} / \mathrm{Nm}^{3}$ & 0,1 & 0.1 & 0.4 & 30.000 & Safe \\
Oxidan $\left(\mathrm{O}_{3}\right)$ & $\mu \mathrm{g} / \mathrm{Nm}^{3}$ & 0.3 & 0.7 & 0.8 & 235 & Safe \\
Hydrogen Sulfide $(\mathrm{H} 2 \mathrm{~S})$ & $\mathrm{ppm}$ & 0.002 & 0.002 & 0.002 & 0.02 & Safe \\
Total Dust (TSP) & $\mu \mathrm{g} / \mathrm{Nm}^{3}$ & 1.78 & 1.96 & 1.27 & 230 & Safe \\
\hline
\end{tabular}

The increasing number of Aedes aegypti mosquito mortality after exposure caused by compounds content of Legiayu incense. By $45 \%$ silica compounds enable to inhibit the development of Aedes aegypti larvae. Silica compounds is stomach poison, respiratory poison, and contact poison. Silica compounds work by inhibiting the metabolism and synthesis of cells, one of which is transport electrons contained in mitochondria. This results in a decrease in cell performance in producing energy used as a food source of larvae (Vasantha-Srinivasan et al., 2018). Legiayu incense ash contains compounds of silica, polyphenols, saponins, alkhaloids as bioactive substances that slow the development of larvae. The bioactive substance interferes with the response and excitatory of eating insects. Receptors in the mouth area will be inhibited and the larvae lose excitation to the surrounding nutrients (Sholeha et al., 2018). Saponins and alkaloids compounds as stomach poisoning by inhibiting the working system of enzymes cholinesterase in larvae (Rochmat et al., 2017). Polyphenol compounds as digestive toxins work by inhibiting the work of cell metabolism processes (Astriani and Widawati, 2017). Flavonoid and tannin compounds act as a respiratory toxin in larvae, inhibiting respiration and nerve wither (Susilowati et al., 2018). Flavonoid and tannin are able to provide toxic effects that are able to clump the protein of Aedes aegypti larvae. Flavonoid compounds are able to regulate proteins that result in the permeability of the cell walls of larvae decreased which has an impact on the loss of excitatory stimulus of eating and larvae experience death (Bao et al., 2018; Siew et al., 2019).

\section{Legiayu incense product toxicity test}

Environmental toxicology testing of Legiayu incense smoke and ash at seven parameters and three different locations revealed that the smoke and ash met environmental quality standards (Table III).

The environmental toxicity tests for the safety of Legiayu incense smoke and ash based on 7 parameters with 3 different locations (the laboratory (A298), in the outside area of the laboratory (A299) and in residential areas (A300), showed that $\mathrm{PM}_{2.5}, \mathrm{NO}_{2}, \mathrm{SO}_{2}, \mathrm{CO}, \mathrm{O}_{3}, \mathrm{H}_{2} \mathrm{~S}$, and TSP have meet the minimum standard values and meet the criteria of environmental quality standards and are safe to use indoors and outdoors. In accordance with Government Regulation of the Republic of Indonesia Number 22 of 2021, Bali Governor Regulation number 16 of 2016, and Indonesian National Standard 06-3566-1994 (Indonesian National Standards, 1995). Legiayu incense products are feasible and safe to use as insecticides and larvacides to minimize the population of Aedes aegypti mosquito. 

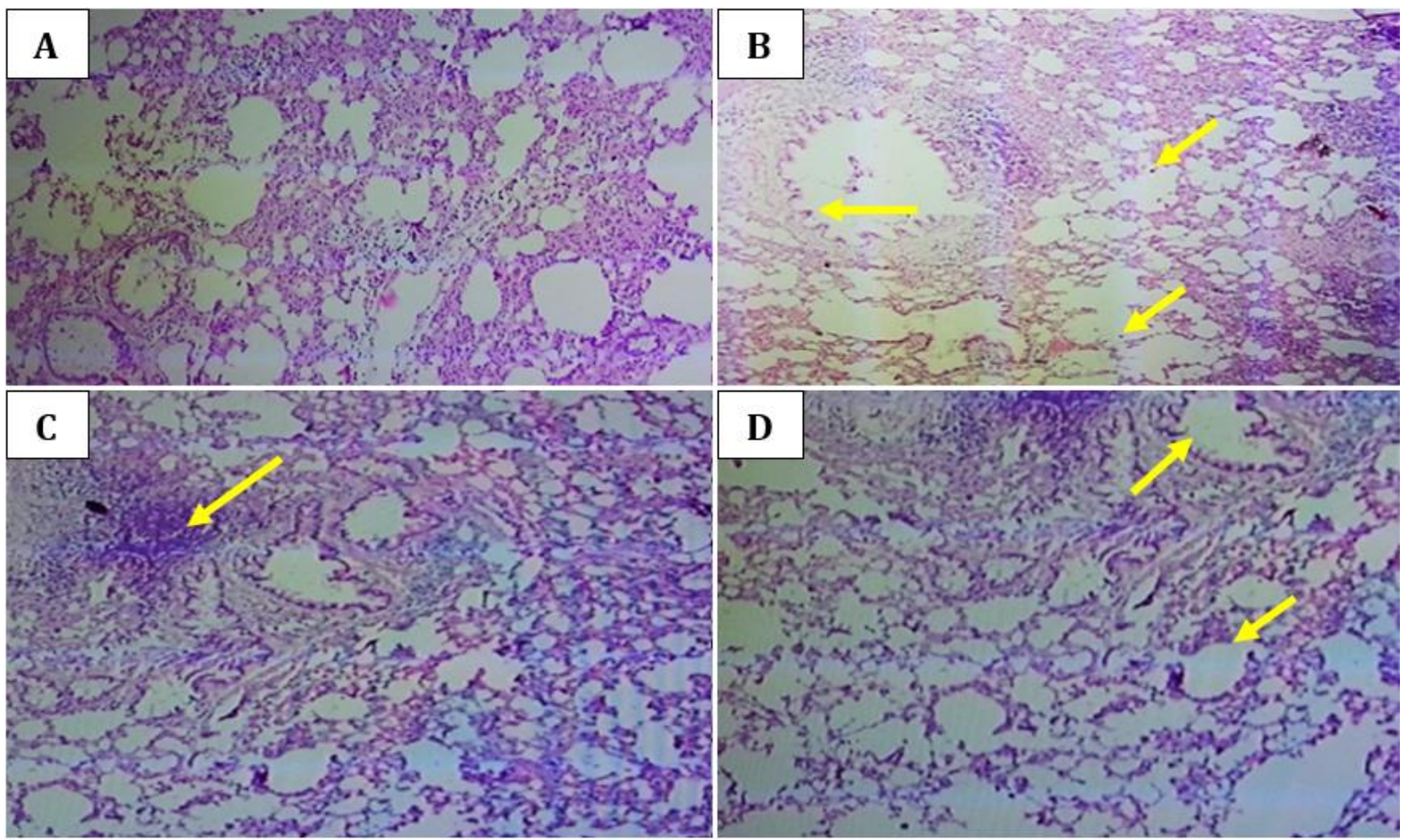

Figure 3. Mice lung tissue given exposure to Legiayu incense smoke for 12 weeks.

Note: $\mathrm{A}=$ Before the trial, the tissue with in lungs is normal (Control); $\mathrm{B}=$ after 4 weeks of treatment (Lymphoid cells found in the alveoli); $\mathrm{C}=$ after 8 weeks of treatment (Found lymphoid foci in the alveoli); $\mathrm{D}=$ after 12 weeks of treatment (The alveolar cavity remains unchanged).

\section{Lung tissue histology overview mice (Mus musculus) strain Balb/C}

The sub-acute toxicity tests (Figure 3 ) at the Food and Drug Administration showed Legiayu incense smoke did not result in histological changes in the mice lung tissue (Mus musculus) exposured for 40 minutes each day within a period of 12 weeks. The sub-acute toxicity tests at the Food and Drug Administration (BPOM) showed Legiayu incense smoke did not result in histological changes in the mice lung tissue (Mus musculus) for exposure 40 min each day 12 weeks periods. The picture of preparations colored using Haematoksilin-Eosin ${ }^{\circledR}$ appears to be non-inflammatory in the lung tissue of test animals, judging by the absence of polymorfonuclear cells (Granulocytes), edema and mononuclear cell infiltration in pulmonary tissue morphology. The observed results showed no changes in tissue morphology (degeneration), absence of cells experiencing necrosis, hyperplasia and metaplasia this has met the standard criteria OECD test number 413 Subchronic Inhalation Toxicity: 90-day Study, SNI 06-3566-1994 and Food and Drug Administration regulations number
7 of 2014 (Food and Drug Administration Republic of Indonesia, 2014).

\section{CONCLUSION}

Legiayu incense products are potensial insecticides and larvicides against Aedes aegypti mosquitoes and potensial as a substitute for mosquito repellent and synthetic incense. The effects of sub-chronic toxicity should be done to determine its long-term safety, for further research.

\section{ACKNOWLEDGEMENT}

We would like to thank the Department of Biology, Hindu University of Indonesia Denpasar for their technical support and all the contributors who helped in this study.

\section{REFERENCES}

Aji, R., 2017. The Effect of Lemongrass on the Existence of Aedes Aegypti Larvae in Water Collections. J. Vokasi Kesehat. 3, 1-4.

Amador-Muñoz, O., Martínez-Domínguez, Y.M., Gómez-Arroyo, S., Peralta, O., 2020. Current 
situation of polycyclic aromatic hydrocarbons (PAH) in PM2.5 in a receptor site in Mexico City and estimation of carcinogenic PAH by combining non-realtime and real-time measurement techniques. Sci. Total Environ. 703, 134526.

Astriani, Y., Widawati, M., 2017. Potential Plants in Indonesia as Natural Larvicides for Aedes aegypti. Spirakel 8, 37-46.

Bali Health Department, 2020. Bali Province Health Profile 2019. Bali Provincial Health Office, Denpasar.

Bao, F., Tang, R., Cheng, L., Zhang, C., Qiu, C., Yuan, T., Zhu, L., Li, H., Chen, L., 2018. Terpenoids from Vitex trifolia and their antiinflammatory activities. J. Nat. Med. 72, 570575.

Chan, E.W.C., Baba, S., Chan, H.T., Kainuma, M., Tangah, J., 2016. Medicinal plants of sandy shores: A short review on vitex trifolia L. and ipomoea pes-caprae (L.) R. Br. Env. Heal. Perspect 124, 1487-1492.

Darwin, M., Mamondol, M.R., Sormin, S.A., Nurhayati, Y., Tambunan, H., Sylvia, D., Adnyana, I.M.D.M., Prasetiyo, B., Vianitati, P., Gebang, A.A., 2021. Quantitative approach research method, 1st ed. CV Media Sains Indonesia, Bandung.

Ekawati, E.R., 2017. Utilization of Liny Orange Fruit (Citrus Aurantifolia) Skin as Larvacides Aedes Aegypti Instar III. Biota 3, 1-11.

EPA, 2014. Emission Factors for Greenhouse Gas Inventories, International Regional Science Review. Environmental Protection Agency (EPA).

Fitriansyah, Irfan, M., Indradi, Bayu, R., 2018. Phytochemical Profile and Pharmacological Activity of Baluntas (Pluchea indica L.). Farmaka 16, 337-346.

Food and Drug Administration Republic of Indonesia, 2014. Regulation of the Head of the Food and Drug Supervisory Agency of the Republic of Indonesia Number 7 of 2014 concerning Guidelines for In Vivo NonClinical Toxicity Testing.

Garcia, G. de A., David, M.R., Martins, A. de J., Macielde-Freitas, R., Linss, J.G.B., Araújo, S.C., Lima, J.B.P., Valle, D., 2018. The impact of insecticide applications on the dynamics of resistance: The case of four Aedes aegypti populations from different Brazilian regions. PLoS Negl. Trop. Dis. 12, e0006227.

Geng, Y., Hu, G., Ranjitkar, S., Shi, Y., Zhang, Y., Wang,
Y., 2017. The Association of Domestic Incense Burning with Hypertension and Blood Pressure in Guangdong, China Xiuling. Int. J. Environ. Res. Public Health 14, 1-12.

Guo, S.E., Chi, M.C., Lin, C.M., Yang, T.M., 2020. Contributions of burning incense on indoor air pollution levels and on the health status of patients with chronic obstructive pulmonary disease. PeerJ 8, 1-17.

Hung, D.Z., Yang, K.W., Wu, C.C., Hung, Y.H., 2020. Lead poisoning due to incense burning: an outbreak in a family. Clin. Toxicol. 1-4.

Indonesian National Standards, 1995. Regulation of the National Standardization Agency of the Republic of Indonesia 06-3566-1994 regarding Fuel Type Mosquito Eradication Products.

Jerry, J., Collins, G., Streem, D., 2012. Synthetic legal intoxicating drugs: The emerging "incense" and "bath salt" phenomenon. Cleve. Clin. J. Med.

Marcombe, S., Mathieu, R.B., Pocquet, N., Riaz, M.A., Poupardin, R., Sélior, S., Darriet, F., Reynaud, S., Yébakima, A., Corbel, V., David, J.P., Chandre, F., 2017. Insecticide resistance in the dengue vector aedes aegypti from martinique: Distribution, mechanisms and relations with environmental factors. PLoS One 7, e30989.

Mayasari, R., Arisanti, M., Nurmaliani, R., Sitorus, H., Ambarita, L.P., 2020. Characteristics of patients, days and rainfall on the incidence of Dengue Fever in Ogan Komering Ulu District. J. Heal. Epidemiol. Commun. Dis. 5, 23-29.

Ministry of Health, 2018. The Situation of Dengue Fever Disease in Indonesia 2017, Infodatin: Data and Information Center of the Ministry of Health of the Republic of Indonesia. Indonesian Ministry of Health, Jakarta.

OECD, 2009. Organisation for Economic Cooperation and Development (OECD) Guidelines for Chemical Testing, Section 4: Health Effects Test Number 403: Acute Inhalation Toxicity.

OECD, 2018. OECD Guidelines for Chemical Testing, Section 4: Health Effects Test Number 413: Subchronic Inhalation Toxicity: 90-day Study.

Rochmat, A., Adiati, M.F., Bahiyah, Z., 2017. Development of Aedes aegypti Mosquito larvae Biolarvicide with active ingredients of Beluntas Extract (Pluchea indica Less.). 
Reaktor 16, 103.

Saklani, S., Mishra, A.P., Chandra, H., Atanassova, M.S., Stankovic, M., Sati, B., Shariati, M.A., Nigam, M., Khan, M.U., Plygun, S., Elmsellem, H., Suleria, H.A.R., 2017. Comparative evaluation of polyphenol contents and antioxidant activities between ethanol extracts of vitex negundo and vitex trifolia L. Leaves by different methods. Plants 6, 45.

Saputra, E.J., Pakkan, R., 2018. The Effectiveness of Lime Leaf Extract (Citrus aurantifolia) and Fragrant Lemongrass Stem (Cymbopogon nardus L) Against Death of Aedes aegypti larvae in Lapulu sub-district, Abeli subdistrict. Miracle J. Public Heal. 1, 1-8.

Sholeha, D.., Muhamat, M., Anwar, K., 2018. Activity Test of Beluntas Leaf Petroleum Ether Fraction (Pluchea indica (L.) Less.) As Larvicide against Aedes aegypti Mosquitoes. J. Pharmascience 5, 86-97.

Siew, Y.Y., Yew, H.C., Neo, S.Y., Seow, S.V., Lew, S.M., Lim, S.W., Lim, C.S.E.S., Ng, Y.C., Seetoh, W.G., Ali, A., Tan, C.H., Koh, H.L., 2019. Evaluation of anti-proliferative activity of medicinal plants used in Asian Traditional Medicine to treat cancer. J. Ethnopharmacol. 235, 75-87.

Susilowati, R.P., Darmanto, W., Aminah, N.S., 2018.

The Effectiveness Of Herbal Mosquito Coils
"MORIZENA" Against Aedes aegypti Death. Indones. J. Trop. Infect. Dis. 7, 50.

Vasantha-Srinivasan, P., Thanigaivel, A., Edwin, E.S., Ponsankar, A., Senthil-Nathan, S., Selin-Rani, S., Kalaivani, K., Hunter, W.B., Duraipandiyan, V., Al-Dhabi, N.A., 2018. Toxicological effects of chemical constituents from Piper against the environmental burden Aedes aegypti Liston and their impact on non-target toxicity evaluation against biomonitoring aquatic insects. Environ. Sci. Pollut. Res. 25, 1043410446.

WHOPES, 2018. World Health Organization Pesticide Evaluation Scheme.

Wong, A., Lou, W., Ho, Kin fai, Yiu, B.K. fung, Lin, S., Chu, W.C. wing, Abrigo, J., Lee, D., Lam, B.Y. ka, Au, L.W. chi, Soo, Y.O. yan, Lau, A.Y. lun, Kwok, T.C. yui, Leung, T.W. hong, Lam, L.C. wa, Ho, Ko, Mok, V.C. tong, 2020. Indoor incense burning impacts cognitive functions and brain functional connectivity in community older adults. Sci. Rep. 10,1-11.

Zulfikar, Aditama, W., Sitepu, F.Y., 2019. The effect of lemongrass (Cymbopogon nardus) extract as insecticide against Aedes aegypti. Int. J. Mosq. Res. 6, 101-103. 